\title{
Uma possível leitura do universo fordiano em "O Homem que Matou Liberty Valance"
}

\author{
Manuel Bernardo Cabral \\ Direção Regional da Cultura, Portugal
}

\begin{abstract}
Author in the true sense of the word, John Ford has created a very particular universe, which can be found in his films, through which he seeks to decode and question his usual themes such as civilization and progress, community, legends and myths in the historical construction, freedom and free will, law and order, education, and other ones that have to do with the civilizational process and its human and social dimension. Using western as his film genre of choice in the recurring approach to these themes, Ford gives his filmography, even when he leaves his comfort zone in the western, a distinctive and identifiable stamp, in which he uses masterfully the elements of filmic construction, to build a body of work cohesive and fully deserving of the classification of author cinema.

"The Man Who Shot Liberty Valance", is one of his last and most significant films, where all these themes meet, intersecting in a critical analysis of US History, where Ford is not deterred from a moral judgment.

With the analysis of this film, it is intended to cast a glance, not only at the film in question, but also, and through the film, at the recurring themes of Ford's universe, which are treated here with the maturity of a great filmmaker at the end of his career, who has long decanted to perfection his ability to tell meaningful stories through the seventh art.
\end{abstract}

Keywords: Western, Civilization, Law \& Order, Liberty, Education

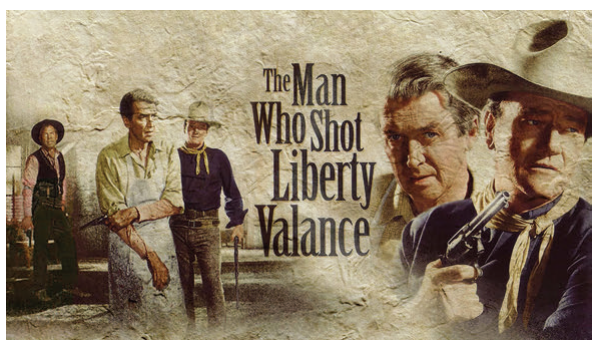

moviesrankings.coM

\section{Introdução}

Autor na verdadeira aceção da palavra, John Ford criou todo um universo muito particular, que encontramos em filme atrás de filme, através do qual procura descodificar e questionar os seus temas habituais, como civilização e progresso, comunidade, lendas e mitos na construção histórica, liberdade e livre arbítrio, lei e ordem, educação, e outros que tenham a ver com o processo civilizacional e a sua dimensão humana e social, como nos refere André
Bazin: "John Ford conseguia o equilíbrio perfeito entre os mitos sociais, a evocação histórica, a verdade psicológica e a temática tradicional da realização western." (Bazin 1992, 243). Com efeito, utilizando o western como o seu género cinematográfico de eleição na abordagem recorrente dessas temáticas, Ford dá à sua filmografia, mesmo quando sai da sua zona de conforto no western, um cunho distinto e identificável, em que utiliza com maestria os elementos de construção fílmica, na construção de uma obra coesa e plenamente merecedora da classificação de cinema de autor.

Produzido em 1962, The Man Who Shot Liberty Valance, em português "O homem que matou Liberty Valance", é um dos últimos filmes da carreira de John Ford, e um dos mais significativos, onde todas essas temáticas se encontram, cruzando-se numa análise crítica à História dos EUA, onde Ford não se coíbe de um julgamento moral dessa mesma História. Com "O Homem que matou Liberty Valance", Ford faz uma espécie de autocrítica à sua obra anterior, num auto criticismo também presente noutras das suas obras tardias, como "A Desaparecida" ${ }^{1}$ e "O Grande Combate" 2 , onde se manifesta, tal como em "Liberty Valance", não pela adoção de novos temas ${ }^{3}$, mas sim pela adoção de uma nova perspetiva no tratamento de temas já familiares na obra fordiana.

Com John Wayne, James Stuart, Lee Marvin e Vera Miles nos principais papéis, "O Homem que Matou Liberty Valance" é a pedra angular nessa reflexão crítica de Ford sobre o seu próprio trabalho, congregando em si o habitual universo fordiano, numa autêntica parábola onde se confrontam o oeste, rude, selvagem, violento e livre, com o leste, símbolo do progresso, da imposição da lei e da ordem, da educação do povo e do fim da liberdade individual, Em suma, símbolo do processo civilizacional. Estes temas recorrentemente presentes na filmografia fordiana, voltam a ocupar aqui o lugar central, só que agora analisados sob uma perspetiva amarga, por alguém que os questiona, e se interroga se esses valores, por importantes que sejam, valem o alto preço pago por eles. A questão de Ford aqui é simples: valerá a imposição da lei, da ordem e do progresso, o sacrifício da liberdade?

Uma análise profunda e completa de qualquer filme, para além de se debruçar sobre a soma das partes, deverá também ter em consideração as diversas áreas da construção cinematográfica, desde o guião e os seus componentes, passando pela cinematografia, sonoplastia, cenografia e décor, música, direção de atores, mise-en-scène e montagem, já para não falar de guarda-roupa e efeitos especiais. No entanto, atendendo a que neste trabalho pretendemos abordar o universo fordiano, não teremos uma análise detalhada e exaustiva de todas essas componentes, mas apenas de alguns dos aspetos mais significativos 
para a abordagem desse mesmo universo. Para além disso, teremos uma análise mais sistematizada de uma cena do filme, "a sequência do bife", cena crucial pela sua dinâmica e significado e para a desmontagem do filme e do modo como as temáticas do universo de John Ford são aqui tratadas.

\section{Estrutura e progressão da narrativa}

"O Homem que Matou Liberty Valance" narra a história do Senador Ransom Stoddard, que regressa à cidade de Shinbone com a sua esposa Hallie, para assistir ao funeral de um certo Tom Doniphon. Questionado pela imprensa local sobre o porquê de um senador dos EUA no funeral de um vadio bêbado como Doniphon, Stoddard conta a história do homem que matou Liberty Valance. A verdadeira história do homem que matou Liberty Valance, que é a história de como o velho oeste dos heróis míticos e da liberdade individual dá lugar aos valores vindos do leste e se torna num mundo civilizado.

John Ford desenvolve esta narrativa em dois espaços cronológicos diferentes: o presente onde a narrativa começa e acaba, e o passado, que é um longo intermezzo introduzido por um flashback e onde se desenrola a verdadeira história. Esses dois espaços cronológicos inserem-se numa estrutura narrativa dividida em seis partes.

Parte I - Introdução: Nesta parte são apresentados alguns dos personagens principais: o senador e a sua esposa, Link Appleyard o cocheiro, Pompey e Tom Doniphon, este último na forma de um caixão. As questões levantadas pela imprensa local acerca de Doniphon estabelecem o motivo da narrativa do senador, e portanto, do flashback para o passado.

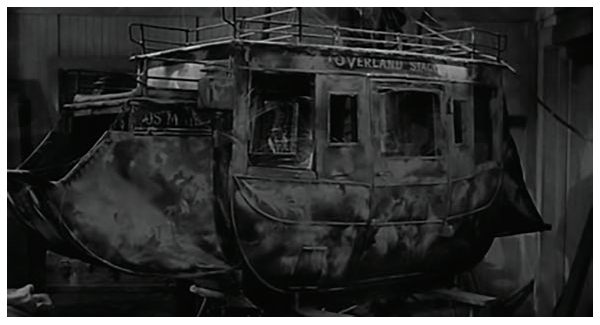

revistacinetica.com.br

Parte II - Começa com o flashback para o passado, quando o senador começa a narrativa. Este flashback usa uma velha diligência como meio de transporte do espectador para o passado. A última imagem da primeira parte é um plano da velha diligência na oficina do carpinteiro/gato-pingado e a primeira imagem da segunda parte, já no passado, é também da diligência. É como se Ford transformasse esse vetusto meio de transporte numa máquina de viajar pelo tempo.

Esta segunda parte é muito importante para a estrutura da narrativa. Começando com o assalto da diligência por Liberty Valance e os seus homens, acaba quando Stoddard, na cozinha do restaurante, aceita a oferta de Peabody para estabelecer o seu cartório nas instalações do jornal. Nesta parte o espectador é apresentado aos restantes personagens, e os elementos internos da narrativa são estabelecidos. Desde a cena do assalto à diligência, os valores da lei escrita e da ordem, vindos do leste e incarnados por Stoddard com os seus livros de leis, são ameaçados pela lei selvagem do oeste, baseada na força. Dois mundos diferentes colidem nesta parte: o leste civilizado e o oeste selvagem. Um mundo real contra um mundo mítico. E é a história dessa colisão que o espectador irá presenciar até ao fim do filme.

Parte III - Esta parte começa com Ransom Stoddard a chegar ao jornal e termina com Liberty Valance a desafiá-lo para um confronto armado ou a deixar a cidade. Durante toda a segunda parte a filosofia da lei do oeste esteve em evidência. Primeiro durante o assalto à diligência, depois na confrontação de Doniphon e Valance na cena do bife, que, com já referimos, devido à sua importância analisaremos em pormenor mais adiante, e finalmente na cena da cozinha, em que Stoddard é aconselhado a aprender a atirar ou a deixar a cidade. Agora, nesta parte é a filosofia da lei do leste que vai evidenciar-se, com o artigo de Mr. Peabody no jornal, a cena da escola e a reunião para as eleições. É uma filosofia de palavras contra uma filosofia de ação. Mas durante esta terceira parte, tal como na segunda, os valores do leste não são suficientemente fortes para se imporem aos do oeste. Todas as vezes que os dois mundos colidem, Stoddard, como personificação do leste, mostra-se inseguro e fraco, a sua atuação e as suas armas inadequadas para lutar nesse mundo que o rodeia. Por outro lado, Valance e Doniphon são fortes, seguros de si, adequados ao ambiente, pois fazem parte integral dele.

Parte IV - Aqui assiste-se ao triunfo da lei do oeste. A destruição do jornal por Valance é a prova simbólica disso. Mesmo o duelo entre Stoddard e Valance é uma vitória para os valores do oeste. Stoddard não conseguiu lutar com Valance segundo os seus próprios valores. A sua escolha é deixar a cidade ou lutar de acordo com as leis e valores do oeste. Ele é o intruso e para impor os seus valores civilizacionais do leste, tem que se submeter primeiro aos do oeste.

Parte V - Liberty está morto. Tom Doniphon perde a sua identidade e desiste da sua namorada Hallie a favor de Stoddard. É o triunfo do leste sobre o oeste selvagem. Mas é um triunfo intolerável, pois não foi conseguido de acordo com os seus valores. Somente a revelação de Tom de que ele, Ransom, na realidade não matara Liberty Valance, Ihe permite ficar e aceitar a nomeação de candidatura ao senado e a mão de Hallie. Portanto, os valores do leste não venceram os do oeste. É o próprio oeste, na pessoa de Doniphon, que os matou, ao destruir Liberty e o seu mundo, o único onde ele próprio poderia existir. E ele fá-lo a pedido de Hallie, a rapariga que ama, e que também representa aqui o ethos do velho oeste, embora de uma forma diferente de Tom e Valance. Ela representa um velho oeste ansioso por ser civilizado, domesticado, "lesticizado". E matando Liberty, Tom oferece-lhe aquilo que ela mais deseja e que ele 
pensa ser o melhor para ela e para o mundo que ela representa, mesmo significando a sua destruição.

Parte VI - De volta ao presente o senador termina a sua história. Mas o diretor do "Shinbone Star" decide não publicá-la, pois eles estão no oeste, e no oeste "quando o mito se torna facto, publica-se o mito". Portanto a mentira sobre a qual o oeste se civilizou continua a passar por verdade. "Nada é demasiado para o homem que matou Liberty Valance" diz o cobrador do comboio no fim, perpetuando assim o mito.

\section{As personagens}

Tom Doniphon, o herói do filme, é um herói típico do universo fordiano. Duro e forte como uma rocha, seguro de si, é também gentil e desinteressado, capaz de ajudar sem esperar nada em retorno. Ele tem as qualidades de um verdadeiro cavaleiro medieval. Mas todas essas qualidades tornam-no incapaz de funcionar numa sociedade inteiramente organizada. Ele necessita de espaço e liberdade para exercer o seu poder e a sua generosidade. Numa sociedade inteiramente organizada e ordeira, as suas qualidades e o seu poder não tem razão de existir nem podem ser exercidos.

O mesmo acontece com Liberty Valance, o fac similae demoníaco de Doniphon. Como ele, Valance também necessita de um mundo caótico e sem lei para sobreviver, e juntos, eles representam esse mundo. Mas há uma grande diferença entre os dois homens. Doniphon possui o livre arbítrio, ou seja, o poder de escolha entre o bem e o mal, o poder de escolha dos seus valores e de decisão sobre as suas ações. Isso permite-lhe tornar-se na força de mudança na cidade de Shinbone. Afinal é ele que cria as condições que civilizarão a cidade, e não Ransom Stoddard, embora seja este último quem colhe os louros. Liberty Valance, por outro lado, é um prisioneiro da sua personalidade demoníaca. Ele não tem escolha. As suas ações só podem existir dentro desse padrão do mal. Mas dentro desse padrão maléfico, ele tem a liberdade (liberty) do exercício do seu poder. E é por isso que ele vai reagir com tamanha fúria aos livros de leis de Stoddard. Eles representam uma ameaça à sua liberdade (liberty), ao livre exercício do seu poder.

Uma personagem interessante para comparar com Valance e Doniphon, é Ethan Edwards do filme "A Desaparecida". Ele tem a mesma força e autoconfiança destes dois e também necessita dos espaços abertos e dum mundo sem ordem para ser ele próprio. Mas a sua personalidade tem um aspeto diferente. Ele possui a frieza, autoconfiança e bondade desinteressada de Tom Doniphon, mas tem também a crueza e maldade de Liberty Valance. Ele combina ambos os aspetos, e é o protagonista da sua própria luta interna entre o bem e o mal, o que o transforma numa personagem muito mais rica e complexa, conseguindo no fim ultrapassar o seu lado mau. Valance, sendo uma personagem apenas com uma dimensão (a personificação do mal), não tem essa possibilidade, e Doniphon não necessita de o fazer, pois não só personifica o bem, como também a sua luta não é consigo mesmo.

Ransom Stoddard, a personagem que representa os valores do leste nesta narrativa é o oposto das personagens anteriores. É fraco, inseguro, incapaz de sobreviver sozinho num mundo sem ordem nem lei. Ele só pode existir num mundo regulado por palavras pois domina-as bem, e o mundo das leis e da ordem é um mundo de palavras. No mundo do oeste Ransom depende de outro para sobreviver. Embora lute e se rebele contra essa dependência, ele é impotente fora do mundo da lei e da ordem. Mas há uma qualidade que partilha com Valance, Tom e Ethan Edward de "A Desaparecida": coragem. Stoddard não é um cobarde. Vendo que não pode lutar contra Valance com a lei das palavras, e vendo o resultado da lei da selva que este impõe, na destruição do jornal e no espancamento de Mr. Peabody, ele decide enfrentá-lo no seu próprio terreno e nos seus próprios termos, sabendo que não tem a mínima hipótese. Nesta sequência Stoddard eleva-se acima dos outros. Mas coragem não é o único atributo de Ransom Stodard; a vaidade é outra das suas características e provavelmente a fonte da sua coragem. É também a vaidade que o faz aceitar construir a sua vida e a sua carreira numa glória que pertence a outro. E essa vaidade está bem patente nas suas atitudes com a imprensa quando retorna à cidade para o funeral. Só a presença da verdade na forma do caixão de Tom o torna um pouco mais humilde. Mas no fim, quando o revisor do comboio diz que "nada é demasiado para o homem que matou Liberty Valance", ele volta a ser o político cheio de orgulho e vaidade. E foi para dar lugar a políticos vaidosos e ao mundo que representam, que Tom Doniphon e os seus valores simples foram destruídos.

Hallie, a mais importante personagem feminina neste filme, tem um papel muito interessante. Ela também representa o mundo do oeste, mas não exatamente o mesmo oeste que Tom e Valance. Ela existe no mesmo espaço que eles, e também é livre e espontânea como eles. Mas a sua feminilidade torna-a diferente, e fá-la sonhar com um mundo diferente, um mundo a que Mrs. Jorgensen de "A Desaparecida" se refere quando diz: "Um dia este país vai ser um belo lugar para se viver". $\mathrm{E}$, como na maioria dos filmes de Ford, será ela como mulher que vai ser o fator humanizador, opondo-se à violência e tornando-se no catalisador dum processo civilizacional, que para Ford significa a criação dum mundo de paz, harmonia, progresso, obediência à lei, ordem e respeito pela propriedade privada.

Se nos filmes de Ford as mulheres são geralmente os agentes civilizacionais, ou pelo menos os catalisadores desse processo, a educação é o processo de atingir essa civilização. E com Ford mulheres e educação estão interligados. Em "A Desaparecida" Mrs. Jorgense tinha sido professora primária. Em "O Grande Combate" Deborah Wright é também professora, e aqui o tema da educação está bastante em evidência. $E$ finalmente em "O Homem que Matou Liberty Valance", embora Ransom Stoddard seja o professor, é Hallie, com o seu desejo de aprender e de transformar Shinbone, a força real que inicia a escola.

As predições de Mrs. Jorgensen em "A Desaparecida", concretizam-se em "O Homem que Matou Liberty Valance". Shinbone torna-se "num belo 
lugar para se viver", com lei, ordem e rosas verdadeiras, em vez das rosas selvagens dos catos. Mas para isso Tom e Liberty pagam um alto preço. A sua destruição e a do mundo que amam. Mas eles não são os únicos a pagar. Hallie também paga um preço demasiado elevado pela sua ânsia de progresso e civilização. No fim do filme ela já não é a mulher alegre e espontânea que era quando Stoddard é trazido por Tom pela primeira vez. Agora ela é sossegada, controlada, discreta. $E$ isso não é devido à sua idade. Essa atitude domesticada começa no passado, na cena da escola, que marca o primeiro passo em direção à civilização.

A importância da personagem de Hallie transcende o seu papel como outra faceta do oeste selvagem. Ela é também o principal meio que Ford usa para questionar o valor da civilização. Através dela as simpatias de Ford vão definitivamente para o lado de Tom, o lado mítico. Isto é particularmente claro no fim. Prestes a deixar a casa funerária, Hallie, ao fundo, é enquadrada pela porta aberta. Ransom, a meio campo olha para o caixão de Tom que se encontra em primeiro plano. Uma rosa selvagem do cato, símbolo do oeste e de tudo o que Tom amava, encontra-se sobre o caixão.

Da imagem da flor do cato, há um Dissolve para um plano médio de Ransom e Hallie no comboio, tendo ao fundo a paisagem a desfilar através da janela. Emocionado Stoddard pergunta-Ihe se ela "gostaria de deixar Washington e voltar a viver em Shinbone". A face de Hallie ilumina-se, e a sua voz transparece esperança e felicidade ao responder: "As minhas raízes estão aqui, o meu coração está aqui". Isto leva Stoddard a perguntar-lhe aquilo que já sabe: "Hallie quem pôs a flor do cato sobre o caixão de Tom?" A sua resposta soa serena: "Fui eu". Para Ransom é a confirmação do seu fracasso, de que não esteve à altura das espectativas que criara nela, e do profundo arrependimento que ela sentia pela escolha que fizera. Escolha que agora é irreversível, pois quando o cobrador do comboio vem e diz que "nada é demais para o homem que matou Liberty Valance", Ransom esquece rapidamente a ideia de voltar a viver em Shinbone, e volta a ser o político vaidoso e cheio da sua importância. Hallie não pode escapar. Está para sempre prisioneira no mundo desapontante do homem que matou Liberty Valance.

\section{Cinematografia e cenografia}

Em relação à cinematografia e cenografia, "O Homem que Matou Liberty Valance" não é um filme muito característico do western de Ford. Os westerns de John Ford são geralmente autênticas celebrações visuais dos grandes espaços da paisagem americana, sendo muitos deles filmados em Monument Valley, seu cenário favorito. O western típico fordiano é uma autêntica balada à grandeza geográfica americana, utilizada plasticamente como metáfora para a grandeza política, económica e militar da América. Isso é patente em "A Desaparecida" desde o início. Enquadrada pela porta que se abre para o exterior, vê-se a silhueta de Marta com a paisagem ao fundo. $E$ essa imensa paisagem vai ser um elemento muito importante ao longo de todo o filme. O rancho dos Edwards é um minúsculo pedaço de civilização perdido numa vastidão selvagem, e acabará por sucumbir às forças dessa vastidão, incarnadas no ataque dos índios. Aliás, olhando para o cenário de «A Desaparecida» vemos que a maior parte das cenas passam-se ao ar livre, o mesmo acontecendo em «O Grande Combate». Neste último caso não poderia ser de outra forma, pois a narrativa versa sobre os índios, e na filmografia de Ford os índios estão sempre associados com a natureza, o que no continente americano significa espaços abertos. Há, portanto, essa constante marcante, quase como uma imagem de marca, do culto pela paisagem do mítico oeste. Aliás, se fizermos uma digressão pela obra de Ford, veremos sempre a presença constante dos grandes espaços abertos nos seus westerns, inclusive no seu famoso "Cavalgada Heróica", de 1939.

No entanto, em "O Homem que matou Liberty Valance" a cinematografia, e principalmente a cenografia, são totalmente diferentes. Os grandes espaços abertos não existem. A maior parte do filme passa-se em interiores, e mesmo as cenas exteriores não têm espaços abertos.

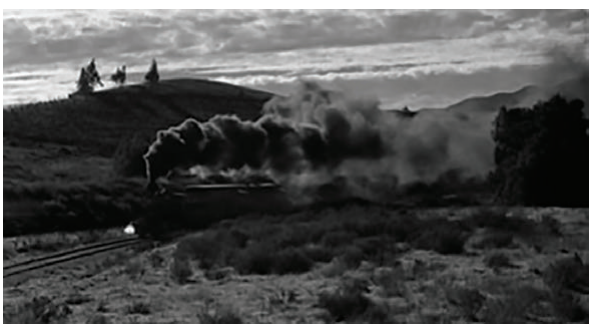

revistacinetica.com.br

Quando o comboio entra no estacão, a paisagem está enclausurada pelas colinas ao fundo.

$\mathrm{Na}$ cena do ataque à diligência, o espaço está delimitado pelas rochas e pela escuridão. Quando Valance começa aos tiros na rua, o seu espaço está confinado pelo saloon e pelo restaurante. Portanto, este é um filme de espaços confinados. Para além da maioria das cenas se passar em interiores, as poucas que se passam no exterior sugerem uma atmosfera interior. E essa sugestão é reforçada pela iluminação. Filmado intencionalmente em preto e branco, o filme usa quase sempre uma iluminação low key, que Ihe imprime um estilo de filme noir, criando grandes contrastes de luz e sombra. Tudo isso se conjuga para dar ao filme uma atmosfera especial, claustrofóbica, que se combina perfeitamente com a narrativa para transmitir o ponto de vista de Ford sobre o tema, já veiculado através da personagem Hallie. E aqui, o ponto de vista de Ford é a mágoa, a nostalgia da perda do passado e a constante interrogação: valerá o nosso presente essa perda? E ao pôr a questão ao longo do filme ele vai, utilizando também a cinematografia e um certo discurso narrativo, dando a sua amarga resposta: foi inevitável e trouxe muitas coisas boas, mas o preço foi demasiado alto. 


\section{A Sequência do Bife}

A análise detalhada de uma cena ou de uma sequência $^{4}$ é sempre uma maneira interessante de explorar o modo como o autor transformou os elementos da construção fílmica (imagem, som, miseen-scène, montagem, etc.) em elementos de uma gramática cinematográfica que lhe serve para veicular as suas teses. Em "O Homem que matou Liberty Valance", a cena do bife é uma das mais dramáticas, e tem um simbolismo visual muito importante para a estrutura e desenvolvimento da narrativa. Por isso iremos debruçar-nos aqui sobre essa sequência.

A sequência do bife começa com uma panorâmica da sala de jantar do restaurante Peter's Place. É um plano de conjunto filmado da perspetiva da porta da cozinha, mostrando a porta da rua no lado esquerdo do écran. Na banda sonora ouve-se o barulho de um lugar público animado, com conversas perdidas, gargalhadas, etc. A porta da rua abre-se e Liberty Valance e os seus homens entram, provocando um abrupto silêncio. Corte para um plano médio de Hallie dando um passo atrás. Plano Americano de Tom e Peabody sentados à sua mesa. Corta novamente para a Panorâmica inicial com Hallie a sair pelo lado direito do enquadramento.

A presença de Liberty Valance é muito pesada em todos esses enquadramentos, mesmo quando não está visualmente presente. O ritmo lento dos cortes e o silêncio absoluto marcam a sua presença. Numa grande angular, Valance aproxima-se de uma mesa e expulsa os ocupantes. A sua voz cortando o silêncio serve de elo de ligação para um Plano Médio do "xerife" a comer na cozinha. O som da voz de Valance fá-lo escapulir-se pela porta das traseiras. Novo corte para o plano anterior de Valance com os seus homens. Enquanto a sua voz continua a fazer-se ouvir a câmara desvia-se para um Plano Médio de Tom Doniphon sentado à sua mesa.

Novo corte, para um enquadramento da porta da cozinha vista da perspetiva da sala de refeições. $\mathrm{Na}$ cozinha, visto através do enquadramento da porta, Stoddard prepara-se para trazer o bife de Tom. Ele entra na sala andando para trás para poder abrir as meias portas de mola sem virar a bandeja, volta-se e para surpreso. Um corte revela-nos um plano de pormenor da mão de Valance batendo com o cabo do chicote na mesa. A câmara recua num travelling revelando Valance de costas com um dos seus homens de frente para a câmara, apontando para trás dele. Este enquadramento representa a perspetiva de Ranse Stoddard, de modo que quando Liberty se volta é Ranse que vê.

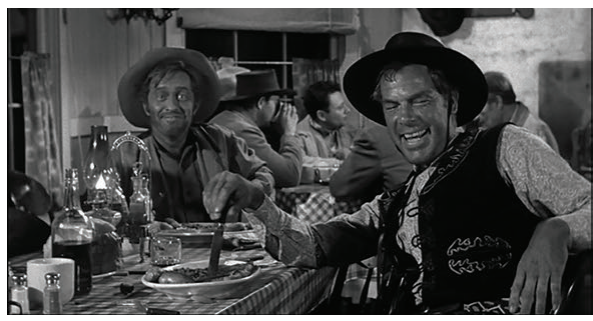

anamorphictil.wordpress.com
E o que ele vê é um Plano Americano de um embaraçado Ransom Stoddard no papel de criado de mesa. Corta para Liberty rindo e lançando piropos à "nova criada". Novamente no plano geral, enquadrado da perspetiva da porta da cozinha com que a sequência começou, vê-se Ranse a atravessar a sala de costas para a câmara, caminhando para o fundo. Quando passa por Valance, é por ele rasteirado. Liberty volta-se para o background para vê-lo cair. Neste momento Doniphon entra no enquadramento ao fundo, vagarosamente e seguro de si mesmo, de frente para Valance (e por consequência para a câmara), dizendo "esse bife era meu Valance". Corta para um Plano Médio de Valance e dos seus homens. Este é o primeiro corte desde que Stoddard saiu da cozinha. Toda a ação deste plano geral desenrola-se perante uma câmara estática. Mas o espectador não se apercebe da estaticidade da câmara, pois o uso da técnica da profundidade de campo $^{5}$, a dinâmica da encenação e a entrada de Tom em cena tornam este enquadramento num quadro vivo e movimentado, e muitíssimo eficiente como começo da parte mais dramática da cena.

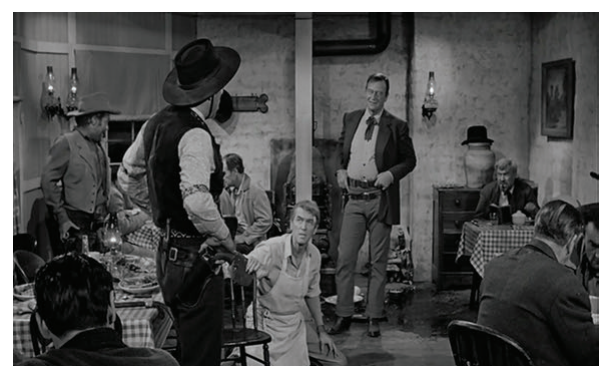

nwfilm.org

A um Grande Plano de Tom segue-se um Plano Médio de Ranse aos seus pés e outro Plano Médio de Valance que diz: "Ouviste-o rapaz. Apanha-o." Plano Médio de Ranse tentando levantar-se dizendo: "Não". Corte para um Grande Plano de Tom: "Espera peregrino. Eu disse tu Valance. Tu é que apanhas o bife." Valance novamente em Plano Médio responde: "Três contra um Doniphon". Esta resposta de Valance é interessante, pois nessa altura ele pensa estar em vantagem sobre Tom, e apesar de ser uma personagem que personifica o mal, não se aproveita disso. Pelo contrário, avisa Tom. Embora sem escrúpulos, ele também segue até certo ponto o mesmo código de honra de Tom, e respeita-o, reconhecendo nele um igual.

A câmara mostra-nos agora uma composição com Valance de costas em primeiro plano, Ranse a meio campo, quase impercetível e Doniphon ao fundo em Plano Médio, apontando para a direita: "O meu empregado Pompey na porta da cozinha". O seu gesto e as suas palavras fazem Valance virar a cabeça naquela direção, servindo de motivação para o corte para Pompey, enquadrado pela porta da cozinha, segurando uma espingarda. Hallie está ao seu lado, mas fora do enquadramento da porta, num simbolismo visual que indica que ela não quer ter nada a ver com o que se está a passar6. 


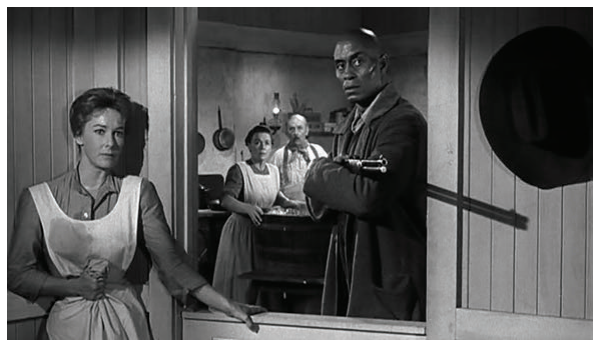

50anosdefilmes.com.br

De volta à ação principal temos novamente um plano geral com Doniphon ao fundo, Valance em Primeiro Plano e Stodard de joelhos no meio dos dois. A composição deste enquadramento é muito significativa, pois Ranse, como representante dos valores da civilização, está de joelhos, impotente, incapaz de qualquer reação eficaz, rodeado pelo oeste forte e dominador.

Para apaziguar a situação um dos homens de Valance tenta apanhar o bife, mas Tom afasta-o com um pontapé: "Eu disse tu, Liberty, tu é que o apanhas". Um corte para um Plano Americano mostra Stoddard ainda entre os dois começando a erguer-se, explodindo de raiva: "O que é isto? Toda a gente nesta região mata à toa?" E abaixa-se novamente apanhando o bife: "Aqui está. Agora está apanhado!"

Esta parte da sequência é muito interessante. Stoddard levantando-se entre Tom e Liberty é quase uma antevisão do final da história. O frágil leste civilizado emerge no meio do forte oeste selvagem. Mas não consegue impor a sua lei. A maneira como Stoddard apanha ele próprio o bife para evitar a confrontação, revela a sua fraqueza. Por aqui se percebe que o triunfo da civilização só será possível pela própria autodestruição do oeste.

Jogo de montagem em Plano Médio de Tom e Liberty. Este atira algumas moedas para o chão virando-se para Tom: "Porque não compras outro bife Doniphon? Eu estou pagando". E virando-se para a assistência: "O espetáculo terminou por agora".

Liberty dirige-se para a saída. Subitamente vira-se, com a mão na arma. Em Grande Plano Tom desafia-o: "Tenta Liberty, tenta". Este desiste e sai com os seus homens. No momento que ele sai, há um corte para um Plano Panorâmico da rua mostrando-o a sair com os seus homens. Este é um exemplo interessante da montagem de continuidade, ou montagem invisível, tão típica do cinema americano. Nós "seguimos" Valance e os seus homens para o exterior e não damos pelo corte. E a mesma montagem invisível está novamente presente quando, já em cima do cavalo, Liberty atira uma garrafa à janela do restaurante. Quando a garrafa atinge a janela há um corte para um Plano Geral do interior do restaurante, de que o espectador não se apercebe, pois na sua mente entrou seguindo a garrafa. Na realidade a montagem invisível está presente em toda a sequência, tanto através do uso da técnica de campo contra campo, com pelo uso do som ou da ação para fazer a ligação dos diversos planos, como acabamos de exemplificar.

No interior do restaurante todos se baixam quando a garrafa quebra o vidro, excepto Tom e Ranse, o que revela uma das qualidades deste último; ele pode não ser capaz de lidar com a lei do oeste, mas não a teme.

O som de tiros leva novamente a ação para a rua, onde Valance e os seus homens disparam à toa, enquanto se afastam. De volta ao plano geral do interior do restaurante, onde o som dos tiros começa a morrer, as pessoas levantam-se lentamente. Corte para um Plano Médio de Tom de costas para a câmara, à esquerda, Mr. Peabody à direita e Ranse, novamente no meio dos dois homens do oeste. Embora a situação agora seja totalmente diferente da anterior, a ideia do civilizado Stoddard estar rodeado do oeste selvagem está novamente em evidência. E o diálogo reforça esta ideia.

Tom: Pergunto-me o que os afugentou?

Peabody: Sabem o que os afugentou? O espectro da lei e da ordem erguendo-se do molho e das batatas esmagadas.

Ransom: Está bem, têm razão. Foram as armas que os afugentaram. A espingarda de Pompey, a tua pistola Tom. Mas que direito tinhas tu de te meteres nos meus assuntos?

Tom: Aquele era o meu bife.

Ransom: E tê-lo-ias morto, ou ele a ti por causa de um bife! Dum miserável bife! Foi por isso que eu o apanhei.

Tom (sarcástico): Obrigado por me salvares a vida peregrino.

Ransom (gritando): Não foi por isso que o fiz. É que não preciso que lutem por mim.

O final deste diálogo é muito importante nesta sequência, pois sublinha verbalmente o que já foi dito por imagens. As alusões de Mr. Peabody acerca "do espectro da lei e da ordem erguendo-se do molho e das batatas esmagadas" são óbvias. As suas palavras e a maneira como são ditas realçam a impotência de Ranse. E este admite-o, dando o crédito às armas. Mas apesar de admitir a eficácia das armas, ele discorda da lei que elas impõem: "E tê-lo-ias morto, ou ele a ti, por causa dum bife! Dum miserável bife!" E continua declarando a sua recusa em ser protegido por essa lei: "Não preciso que lutem por mim". Mas a maneira histérica como fala contrasta com a calma e segurança de Tom, numa indicação clara de que só as armas poderão ditar o final desta narrativa. $E$ bem lá no fundo Ranse sabe-o, e isso magoa-o ainda mais do que o seu orgulho ferido durante toda a sequência.

\section{Conclusão}

"O Homem que Matou Liberty Valance" pode não ser um filme típico de John Ford em termos de cinematografia e de cenografia, ou até mesmo na orientação crítica do seu tratamento temático da narrativa. No entanto continua a ser um filme de Ford no modo como ele manipula a linguagem cinematográfica para transmitir o seu ponto de vista. Como na maioria dos filmes de Ford, "O Homem 
que Matou Liberty Valance" narra duas histórias. À superfície, o filme é mais uma fita de cowboys, com uma diligência, um saloon, os maus da fita, os bons, e todos os ingredientes de qualquer fita do oeste que se preze. Mas a maneira como ele utiliza os elementos e as técnicas cinematográficas para contar essa história, cria uma nova história. A história do processo civilizacional do oeste. Como na maioria dos filmes de John Ford, "O Homem que Matou Liberty Valance" é um filme rico em diversas camadas de significados e interpretações diferentes, convidando o espectador interessado e atento à sua exploração.

\section{Notas finais}

${ }^{1}$ Título original: The Searchers, 1956

2 Título original: Cheyenne Autumn, 1964

${ }^{3}$ Para além dos seus temas habituais, Ford aborda questões como o racismo e o problema índio, tanto em "A Desaparecida", como em "O Grande Combate", onde a questão índia é o tema central.

${ }^{4}$ Sequência é um conjunto de cenas dentro do filme, que em conjunto constituem um todo dramático. Por vezes chama-se cena à sequência, embora a designação seja incorreta.

5 Todos os planos do enquadramento estão em perfeita focagem.

6 Em inglês, frame significa moldura (da porta, neste caso), mas também significa ser envolvido numa determinada situação. Pompey está envolvido na situação, por isso está dentro da moldura da porta. Hallie, pelo contrário não se quer envolver em violências, por isso sai da moldura da porta, e assiste ao lado.

\section{Bibliografia}

Anderson, Lindsay. 1981. About John Ford, London, Plexus

Baxter, John. 1971. The cinema of John Ford, London, A. Zwemmer

Bazin, André. 1992. O que é o Cinema?, Lisboa: Livros Horizonte. ISBN 972-24-0826-7

Gallagher, Tag, John Ford, the man and his films, University of California Press, Berkeley, 1986 https:// books.google.pt/books?hl=pt-PT\&lr=\&id=BaBUDwAA QBAJ\&oi=fnd\&pg=PP7\&dq=john+ford +director\&ots $=M$ 4Ts4Yuxaw\&sig=7FiRqe41 vrYHp2t16lc8OwDfxzl\&red ir_esc $=\mathrm{y} \# \mathrm{v}=$ onepage $\& \mathrm{q}=$ john\%20ford\%20director $\& \mathrm{f}=$ false (acedido a 14/03/2019)

Oliveira, Catarina. 2014. Fronteira da lei: violência e poder em The man who shot Liberty Valance de John Ford e Fatalidade de João Guimarães Rosa. Tese de Mestrado, Faculdade de Letras da Universidade de Lisboa (acedido a 14/03/2019) http://repositorio.ul.pt/ bitstream/10451/24726/1/ulfl161935_tm.pdf;Fronteira

Place, Ann Jane. 1974. The western films of John Ford, Seacaucus, Citadel. 